\section{MEDICINE IN THE WAR.} A RETROSPECTIVE SKETCH.

BY

MaJor-General Sir WILMOT HERRINGHAM, C.B., M.D.

WhEN one looks back upon the nearly five years of war certain recollections stand out, certain experiences of disease and its treatment seem more important than others.

\section{Cerebro-spinal Fever.}

In the first winter, early in January, we saw our first cases of cerebro-spinal fever; few out there had ever seen it in the epidemic form. The British outbreaks had been few and slight, and had occurred at a distance from London. It was a new thing to find strong young men affected, and as we saw more cases the horror of the disease, its unaccountability, our powerlessness to cure it, our inability even to predict its course from day to day, affected us strongly. Sisters were usually changed every fortnight; the disease preyed on their spirits if they nursed it longer.

It was thought that the Canadians brought it with them. 'Their first troops landed just before Christmas, IgI4. But that is doubtful. Cases arose singly from all down the whole of the front. We hardly ever saw two from the same unit, nor could any contact with a previous case be shown. The cases were most distressing to witness. They suffered greatly from pain, were usually unconscious or stupid most of their time, were fed with difficulty, and kept clean with more difficulty still, while herpes and sordes disfigured the skin and the lips. Not much less than half of them died-some quickly, others after a long illness, sometimes with a late onset of vomiting and wasting, which we leained to ascribe to blocking of the canal at the foramen of Magendie and dilatation of the ventricles. In that first winter no serum seemed to have any effect, and not only was treatment powerless but we found ourselves unable to predict even from day to day the course of the disease. A patient would seem to be doing well, and then would relapse and die. Gradually, as Ellis in France and Gordon at home differentiated the strains, serum became more efficacious, but I doubt if under the conditions of active service the mortality ever fell below 35 per cent. The first winter's epidemic was the worst.

A few cases occurred of meningococcal septicaemia a rapialy fatal disease, marked with an abundant rash, high fever, delirium, and pains in the joints and museles. There was no meningeal effusion, but in some instances the meningococcus was grown from the fluid in the ventricles.

\section{The Enteric Fevers.}

The next excitement was the occurrence of a few cases of enteric. There were only two field laboratories out by then. Sydney Rowland, one of the greatest losses of the war (he died in I9I 7 of cerebrospinal fever), was very active in hunting for carriers. Ife found many, and among them a man who had been long kept in an army hospital as a carrier, liad obtained his discharge, had re-enlisted, and was in active service as a regimental cook at the time. The man was rather proud of himself because the had been the subject of questions in the House of Commons.

It was not until some time in the summer of I9I5 that we recognized paratyphoid A readily, but paratyphoid $B$ was known from the first. Paratyphoid A had hardly been seen in England before the war. The rashes are a little different from enteric, and at one time we thought we could distinguish $\mathrm{A}$ and $\mathrm{B}$ by the rash, but that opinion could not hold water. In 1918 an outbreak of gastro-enteritis was ascribed to $B$. paratyphosus $\mathrm{B}$ by the bacteriologists, but as the physicians insisted that the clinical symptoms made that impossible, absorption tests were undertaken, and the bacillus proved to be $B$. aertryck, which had only once before occurred in the United Kingdom, on which occasion also it had been mistaken for paratyphosus $B$ at the time.

The small number and comparative mildness of the cases have been a unique feature in this war. There can be little doubt that inoculation is responsible for it. The French had a very large number of eases until they took to a better system of inoculation, but directly they did the numbers dropped. The type of our cases ruled so mild that we were tempted to ask if the character of the disease had changed. But occasional cases of the old type in uninoculated cases-I remember a French interpreter among others - showed that that was not the reason. Occasionally we would see such a case among the inoculated.

The diagnosis of these cases depended at first upon clinical symptoms, the serological test by agglutination, and cultivation. This was satisfactory until in I9I6 triple inoculation-T.A.B.-began. Then the agglutination test no longer held good in the simple form. Dreyer's metliod, using the Oxford standards and relying only on repeated tests, became the standard method; although there have not been wanting critics both of the detail and of the theory itself, it holds the field as yet.

This work is, indeed, bound up with the great subject of immunity, and it must be remembered that what is, perhaps, the greatest pathological school in the country, that of Glasgow, holds that immunity is something which is not only distinct from any qualities, such as agglutination, that we already recognize, but does not even vary very closely with them.

\section{NEPHRITIS}

In the spring of I9I 5 we began to see an amount of nephritis which, both by its rapid increase and its want of conformity with any conditions, such as weather, likely to account for it, astonished us very much. During I9I5 the greatest number of cases actually occurred in July. Later years, however, showed the greatest prevalence in the autumn and winter, the worst being in the very wet weather of the last thiee months of 19i6. These months were marked by an gutbreak of siffocative bronchitis which was very fatal. We ascribed it then to influenza, though there was no great epidemic at the time. Pfeiffer's bacillus was, in fact, found in a considerable proportion of these cases. But what we felt sure of was that they led to a great increase of, in fact probably accounted for the great increase of, nephritis at the time. The influenza epidemic of I9I 8 confirmed this view.

We had strong suspicions, some of us, that the nephritis of France, which was by no means confined to the trenches or even to the front, was of microbic origin. The curves which it showed suggested it, and it seemed largely unaccountable otherwise. It was prevalent in German and Austrian troops and also with the French. But the Belgians had much less of it. The only parallel outbreak known in the history of military medicine was that which took place in the American civil war. The outbreak in our troops was indubitably far more widespread than anything we had ever seen in civil hospitals, but the cases were as certainly milder. Certiun symptoms, such as 
convulsions, had not the same serious implications that they had at home, and complete recovery took place much more frequently.

In the course of the very careful investigations that were carried on by the Nephritis Committee, Captain Maclean made a contribution to our knowledge of albuminuria in the apparently healthy on a scale (50,000 cases) and with an elaboration never before attempted. And Captain de Wesselow added to our knowledge of dropsy by showing that there was a dropsy of the blood and a dropsy of the tissues which did not necessarily vary together, though they usually did. The observations were novel, and beautifully worked out. The French directed their attention chiefly to the prognosis of the cases. Captain Keith was able to show that a lessened alkalinity of the blood was certainly not the cause of the disease, and in many cases did not occur at all. It seemed both by French and English observations that the prognosis was best tested by experiments on the excretion of certain substances such as diastase or phenolphthalein.

\section{Trench Fever.}

Soon after nephritis became prominent, about May and June, 1915, we began also to recognize that curious disease which has now become well known as trench fever. Major Graham was the first to describe its clinical features. McNee, Hunt, Rankin, and Hurst followed. Unlike nephritis, this was really a disease of the trenches, but was also found frequently in the personnel of hospitals receiving oases from the front.

It was early found by $\mathrm{McNee}$ that it could be inoculated by means of the blood, but facilities for making experiments with volunteers were not available, and up to 1917 the bacteriologists were unable to detect any organic infecting agent. The American Research Committee joined in a committee set up by the Director General in France in that year, and an claborate set of observations and experiments on American volanteers were carried out at a special hospital. The joint committee, besides elaborating the clinical features of the disease, were able to report on March 9 th, I9I8, that the disease was certainly conveyed by lice, and from that time more vigorous measures than before were taken to clean the men from these pests. Good clinical papers by Drummond, Urwick, and Perkins were published in the Quarterly Journal of . Medicine, and the American experiments were fully described by Strong in his large monograph on the disease.

In its typical form the disease is a recurrent fever with a cycle of about five days, characterized by sudden malaise and headache, an evanescent rash of erythematous spots, an enlarged spleen, and pains whose characteristic site is in the shin bones. But the committee was able to sbow that the typical chart admitted of many variations, and thus to bring under one head many cases of fever which, though similar in symptoms, varied greatly in the form of their temperature curve. It may be affirmed that the disease is never fatal, but it was shown that it gives rise, chiefly through cardiac irregularity, to a considerable amount of disablement. In some cases also it lasts a very long time and may lead to invaliding.

Meanwhile a similar committee set up in England has been engaged in an important series of experiments, which show that the poison is contained in the faeces of the infected louse and can be conveyed by rubbing them into a scarified area. This committee has examined the effect of heat and various other physical conditions upon the poison and has greatly added to our knowledge. The infecting agent is still undetermined, and no specific treatment of the complaint has yet been discovered, but it is at any rate known that a rather longer confinement to bed lessens the risk of the tachycardia which is the chief sequela.

It was in IgI6 also that a curious form of febrile jaundice, due to Spirochaeta icterohaemorrhagicu, made its appearance in Flanders. There are several forms of jaundice with fever. That due to enteric was not infrequent, and that due to septic infection was also known. The new form had not previously been observed in Europe, though described by the Japanese. Stokes at the Ypres front and Dawson at the base made careful studies of it. It was hardly ever, if ever, found south of Arras.

\section{Poison Gas.}

It was also in the same year that the Germans first used asphyxiating gas, alleging with their usual disregard of truth in excuse for this action that the French had already employed it. The gas first used was chlorine, which was expelled under pressure and drifted across No Man's Land to the French trenches north of the Ypres salient. A day or two later our troops were similarly attacked. Chlorine was eventually replaced by phosgene.

In July, I917, dichlorethyl sulphide, the so-called mustard gas, was first used in the northern area. And in the same year we began to have cases produced by compounds of chlorarsin, of which that most frequently used was diphenyl chlorarsin.

The action of these gases varied somewhat. Chlorine and phosgene may kill outright; if this does not happen, they cause an oedema of the lungs which, by preventing the oxygenation of the blcod, produces a state of anoxaemia, or want of oxygen, under which the circulation fails. The symptoms are greatly aggravated by muscular exertion, which increases the oxygen want of the tissues. Death rarely takes place if the patient survives the third day. But recovery is often prolonged, and certain symptoms, especially sudden attacks of rapid breathing, may persist for a very long time.

Dichlorethyl sulphide vesicates the skin, sometimes very extensively, and produces large areas of erythema, or of brown pigmentation. It causes intense conjunctivitis and oedema of the eyelids, entirely preventing vision for two or three days. It scorches the mucous membrane of the upper air passages, which when severely affected comes away in the form of sloughs, leaving a very septic raw surface, which by inhalation produces septic bronohopneumonia. The latter is the chief cause of death.

Diphenyl chlorarsin was an altogether less dangerous gas. It sometimes produced intense pain at the back of the nose, and sometimes unconsciousness or stupor, but these effects were transient, and it was not believed to have caused any deaths. Some cuirious nervous symptoms which were observed to occur after it were probably hysterical. Arsenic in quantities that were unmistakably abnormal was recovered from the urine.

The Gas Service rapidly invented a protective cloth helmet, and later a very efficient mask in which the air was respired through a layer of absorbent chemicals. After this was issued casualties arose almost entirely among men who for some reason did not put the mask on sufficiently quickly, or took it off too soon.

We replied effectively with the same weapons, and to good purpose ; the German mask was not so good as our own. In the treatment of the chlorine and phosgene cases by far the most important thing was 
the supply of oxygen. This was first given by the open method through some sort of funnel. But later Dr. Haldane invented an admirable arrangement by which the oxygen under reduced pressure was led through regulating valves to a mask which fitted the face and could be tied in position. It was most valuable in saving life. Venesection was an additional method of treatment which was of undoubted value for cyanotic cases. Cases which were of an ashengrey colour were unfit subjects for bleeding, and even under continuous oxygen administration rarely recovered.

The local effects of dichlorethyl sulphide were mitigated by anodyne inhalations of menthol and chloroform, and by gargles, washes, and wet dressings of weak soda solution. Antiseptics were combined with the anodynes in the hope of preventing the septic 'nflammation of the air passages.

\section{Other Infective Diseases:}

Dysentery did not make its appearance in our army till the late summer of rgi6. It occurred at the base whither it was brought by troops from the East, and at about the same time at the front, where there was some evidence that it was partly due to infection in the German trenches. There was a considerable outbreak of it again in the early summer of 1918 . The amoebic form was vary rare, but both the Flexner and Shiga forms, and also other kindred infeetions were common." The type was not on the whole severe. Antidysenteric serum was found of considerable value in treatment. We had no cases of cholera. The ordinary zymotic diseases-scarlet fever, measles, German measles, mumps, and diphtheria - all occurred as epidemics at different times.

Troops from the East brought malaria with them, and some battalions were badly infected. But regular quinine treatment combined with rest restored them, and they were able to take their place in the line. The quinine was given by the mouth, according to the method recommended by Ross.

\section{Wounds of the Chest.}

Of the greatest interest to all physicians were the wounds of the chest. Such cases are extremely rare in civil practice, and probably not one in five hundred of all the medical officers had ever seen such a case. At first the treatment was wholly expectant. Then we began to aspirate the blood after perhaps a fortnight. In 1916 Major Armstrong reported in favour of aspiration as early as the second or third day. Where feasible this was combined with oxygen replacement. At the end of that year French surgeons, especially Duval, urged a much more daring surgical treatment, and Gray, Gask, and Lockwood led the way in our armies. The first great improvement was the radical cleaning of all sucking or leaking wounds where there was obvious connexion with the open air, and removal of splintered rib, along with thorough evacuation of the contents of the pleura and closure in layers of the thoracic wound. No doubt some of the cases became septic and had to be drained, but many did not, and the gain to the patient was very great, for these cases had been very fatal. The second was the removal of large foreign bodies where accessible. It was proved that the lung could be handled with much less risk than had been sus. pected, and if the new operation was a little overdriven at first this tendency was soon corrected by exporience, and a really great advance in surgery attained.

The medical problems were no less interesting. We found that in such cases the wounded side collapses and the diaphragm rises. The effused blood some- times deposits all its fibrin and remains a defibrinated liquid, though at others clots of the usual kind are found. Aspiration was not followed, as we at first expected, by fresh haemorrhage, and could consequently be practised early. Apart from a severe laceration of the lung, the chief danger lay in septic infection of the haemothorax, and we became skilful in detecting the earliest signs of this condition; which needed prompt surgical interference. Un: looked-for conditions arose on the opposite or un. wounded side. Septic bronchopneumonia from inhalation was not so common as we expected, but hypostatic congestion was not infrequent, and more frequent still was the massive collapse, to which, as a sequel of operations on the abdomen, Pasteur had drawn attention before the war. Bradford and Elliot made important observations upon this and other conditions occurring in the wounded chest.

Gordon Holmes was able to draw up a fine contribution to the physiology and pathology of the cerebellum from his experience of gunshot wounds of the head, and Bradford and Bashford worked out the pathology of a form of epidemic neuritis and polio. myelitis that occurred in the army.

\section{Convalescent Camps.}

In the later years of the war men were drafted from hospitals, as soon as they were well enough, into large convalescent camps, which were for the most part admirably managed. Outdoor games and indoor recreation of all sorts were provided. The aim was to give the men a cheerful and enjoyable time, while strengthening their bodies by regular and at the same time interesting exercise. The old form of physical training was largely replaced by games and by such occupations as gardening or farm work. One convalescent camp had fifty acres of land under cultivation.

\section{Mobile Laboratories.}

A novel feature of this campaign was the importation of bacteriologists and their. laboratories into the front area. Their effect upon the medical work was not easy to express. Not only were they constantly employed to help in the diagnosis of fevers and infections, or in prevention of disease, as by the hunt for carriers of enteric, dysentery, and cerebro-spinal organisms; but they were constant centres of new thought and new effort. Their work was not to be measured by their publications, for they were continually engaged in helping and often stimulating the medical officers who were making fresh observations. Trench fever (McNee), cerebro-spinal fever (Ellis), spirochaetosis (Stokes) were, however, greatly elucidated in these mobile laboratories of the front area, and at the base Dreyer and, later, Perry perfected the diagnosis of enteric, Wright made observations on the resistance of the wound to infections, Martin worked at the problem of dysentery, and many other patho. logists made valuable contributions to medical knowledge.

To this we must add also the constant help afforded by the Medical Research Committeo at homo-not only by the provision of special workers and special apparatus when needed, but also by the constant suipply of all scientific publications produced by physiologists, chemists, and pathologists at fome, and by their continual help through Colonel $T$. R. Elliott in the improvement of note-taking and records of all kinds. The field oard at present in use, which was due to him and to them, is alone an immense stimulus to the medical officers and a great gain to nedical science. 
Preventive Medicine and Sanitation.

It is difficult to do justice to the sanitary side, for their work lay outside the view' of clinical men. But we could all recognize their unceasing efforts to prevent infection from excreta, to purify water, and to deliver the army from the pest of vermin. How difficult the last is no one can know who has not seen an army in the field. The dietary of the army was in the charge of this department, which was able to save great sums of money to the country by reducing the really excessive ration at first issued.

We have passed through a time which, thank God, we shall never see again, under a strain which perhaps we did not really appreciate till it was relaxed. Looking back upon it all, we can say, first, that without any doubt whatever the medical work of the army was extraordinarily well done; second, that those at any rate who were connected with hospitals learned more than they ever learned before; and, lastly, that perhaps the greatest lesson of all was that over this wide area and throughout this immense body of men there was a unity of effort and a fellowship of spirit such as we had never before imagined could exist.

\section{CASUAL'TIES IN THE MEDICAL SERVICES.}

\section{ROYAL NAVY. \\ Died on Service.}

Surgeon Lieutenant M. Merhan, R.N.

Surgeon Lieutenant Michael Meelıan, R.N., died at the Italian Mrlitary Hospital at Venice, of pneumonia, on December 13th. He was the son of the late Mr. Jolnn Meehan of Kildysart, co. Clare, and was educated in the school of the Royal College of Surgeons, Ireland, in Dublin, taking the diplomas of L.R.C.P. and S.I. in 1912. $\mathrm{He}$ entered the navy as surgeon on April 11th, 1913, and at the time of his fatal illness was serving in H.M.S. Earl of Peterborough.

\section{ARMY.}

Died on Service.

Major A. U. PARkhurst, S.A.M.C.

Major Arthur Usk Parkhurst, South African Medical Corps, died of pneumonia at Durban, Natal, on November 27th, aged 48. He was the fourth son of the late Captain Horatio Joln Parkhurst of Pontymoel, Monmouthshire, and was educated at Cardiff and St. Mary's Hospital, Paddington. He took the diploma of L.S.A. in 1901, and served as civil surgeon in the Boer war from the date of his qualification to the end of the war. After practising in Cape Colony and the Orange Free State he settled at Estcourt, Natal. During the present war he went through the campaigns in German South. West Africa (wliere ho lost an eye) and German Eust Africa. He was in command of No. 3 General Hospital, South Africa, for a time, and subsequently of a native hospital of 2,000 beds at Durban.

Captain J. V. Duffy, R.A.M.C.

Captain Joseph Vincent Duffy, R.A.M.C. was reported as having died of influenza while on service at Dar es Salaam, East Africa, in the casualty list published on December 23rd, 1918. He was educated at Glasgow, and took the Scottish triple qualification in 1914, after which he was assistant to Dr. A. M. Walker of Hebburu-on-Tyne, till he took a temporary commission in the R.A.M.C. on August 12th, 1915, and was promoted to captain after a year's service. He had served in Egypt and with the 29th Division at Suvla Bay, and proceeded to France with the Division, being present at the first battle of the Somme. He served later in India and East Africa.

Captain H. R. Lawrence, M.C., S.A.II.C.

Captain Henry Ruthven Lawrence, M.C., Sonth African Medical Corps, died of pneumionia in France on December 14th; 1918, aged 34. He was the only son of the late Dr. T. G. Lawrence, of George, South A frica, and was edncated at Edinburgh, where he graduated M.B. and Ch.B. in 1908, and M.D. in 1910, also taking the diploma of F.R.C.S.Ed. in 1912, and studying at Dublin and Freiburg. He was in practice at Newlands, Cape Province. South Africa, and surgeon to the Victoria Cottage Hospital at Wynburg when the war began, and he at once joined the South African Forces. He served in the campaign in German South-West Africa, and afterwards in France.

\section{Repatriated.}

Captain M. Donaldson, R.A.M.C. (temporary).

Captain E. H. Jones, R.A.M.C. (temporary).

Captain H. R. Jones, R.A.M.C. (temporary).

Captain H. A. Sandiford, R.A.M.C.('I'.F.).

Lieutenant A. M. Clare, R.A.M.C. (temporary).

Lieutenant J. A. Loughbridge, R.A.M.C. (temporary).

\section{Irelanto.}

The First Menber for Queen's University, Belfast. Sir Willias Whitla was elected to represent Queen's University, Belfast, in Parliament, by a majority of 1,369 on a total poll of 1,605 . Sir William Whitla consented to stand in response to an invitation from a large body of graduates of all the faculties. In an address issued on December 4th he expressed his opinion that it would bo the first duty of every man elected to the new Parliament to support unwaveringly the Coalition in their. demands for the restitution of the devastated lands of on: Allies, for indemnities for passenger ships sunk, and for all life and property sacrificed in air raids on undefender cities. He added, however, that he did not conceive it to be the duty of a university representative to consider himself a mere party politician. At the same time lie expressed his conviction that the happiness and prosperity of Ireland could only be maintained as long as slie remained an integral part of the empire. He added that one of the determining factors which had induced him to enter parliamentary life was the totally inadequate representation of the medical profession at Westminster. The establishment of a Ministry of Health with advisory boards, the loousing of artisans, hospital reforms of il sweeping kind; and every bill devised to improve the physical condition of the people, would have his support. He dwelt on the vital importance of Government aid for original research in every department of medicine, and said that scientific research and the teaching of science must be fostered by large and judicious Government grants to the laboratories in the different universities. Finally he expressed himself in favour of local option.

After the declaration of the poll the new member paid a tribute to the good humour of his opponent and spoke in warm terms of the great services to the university of the Vice-Chancellor, Dr. Hamilton, who had courageously maintained in the face of almost universal disapproval the strong claims of Belfast to a university of her own. Sir. William Whitla looked back, he said, with real pride to the fact that he had fought by the Vice-Chancellor's side for this cause, and he shared his satisfaction in seeing the university firmly established, highly successful, and sending a representative to Westminster to watch over her interests along with Ulster and the rest of Ireland. Ho then referred to the hard task of Mr. Finnegan, the secre. tary, in building up the new parliamentary register, having to trace old graduates who, after service all over the enspire, had returned to spend the remainder of their lives in the home islands. The Vice-Chancellor, in the course of a speech bringing the proceedings to an end, said that Sir William Whitla had been appointed to the Cbair of Materia Medica and Therapeutics shortly after his own appointment to be head of the old Queen's College. Sir William Whitla had been elected their representative at a psychological moment of extreme importance; it was an age of reconstruction, and among the matters which at a very early date would call for the attention of Parliament was the reconstrnction of the educational system, from primary education up to the university; and another was the great question of the health of the people.

In connexion with Sir. William Whitla's reference to the difficulty of completing the register, we may take the opportmity of pointing ont that there are still several 